\title{
ANÁLISIS DE LA CONSTRUCCIÓN DE IDENTIDADES COLECTIVAS EN LOS LIBROS DE TEXTO: EL TRATAMIENTO DE LA GUERRA DE LA INDEPENDENCIA EN LAS ÚLTIMAS DÉCADAS
}

\author{
Analysis of the construction of collective identities in textbooks: \\ treatment of the War of Independence in the last decades
}

\section{José Ignacio Ortega Cervigón ${ }^{\varnothing}$ y Juan Esteban Rodríguez Garrido $^{\S}$}

Fecha de recepción: 05/09/2016 • Fecha de aceptación: 12/12/2016

Resumen. Los manuales de Historia influyen en el imaginario individual del alumno, así como en la creación de una memoria colectiva y de unos estereotipos culturales. Del mismo modo, pueden contribuir a estigmatizar una época o a un personaje histórico, o bien a ensalzar para siempre la figura de un determinado monarca o grupo social. El libro de texto ha sido el recurso didáctico más utilizado para el desarrollo de la asignatura de Historia. Las distintas perspectivas de su análisis han propiciado una interesante línea de investigación en Didáctica de la Historia. Por ello, resulta muy interesante prestar atención a la manera en que estos libros han presentado a nuestros escolares la historia, hechos y personajes de la Guerra de la Independencia, al ser esta uno de los procesos históricos más utilizados en la creación y consolidación de identidades colectivas en España. Para obtener una muestra significativa en nuestro estudio, utilizamos ejemplos de las editoriales más representativas y acudimos a textos de Educación Secundaria editados en distintos momentos de las últimas cuatro décadas.

Palabras clave: Educación Secundaria; Libros de texto; Edad Contemporánea; Guerra de la independencia; Identidad.

\footnotetext{
ø Departamento de Didáctica de las Ciencias Sociales. Facultad de Educación. Universidad Complutense de Madrid. C/ Rector Royo Villanova, s/n. 28040 Madrid. España. joseiort@ucm.es.

$\S$ Departamento de Educación. Facultad de las Artes y las Letras. Universidad Nebrija. Campus de Princesa. C/ Santa Cruz de Marcenado, 27, 28015 Madrid.jrodriguezga@nebrija.es.
}

Cómo citar este artículo: Ortega Cervigón, José Ignacio y Rodríguez Garrido, Juan Esteban. "Análisis de la construcción de identidades colectivas en los libros de texto: el tratamiento de la Guerra de la Independencia en las últimas», Historia y Memoria de la Educación, 6 (2017): 203-240. 
Abstract. History manuals influence the individual imaginary of the pupil, as well as the creation of a collective memory and a number of cultural stereotypes. Similarly, they can contribute to the stigmatization of an epoch or of an historical figure, or to their lionization, for all eternity, of the figure of a certain king or social group. The textbook is the most widely used didactic resource for approaching the subject of History. The different perspectives of its analysis have propitiated an interesting line of investigation in Didactics of the History. This is the reason for our interest in scrutinizing the way in which these books have presented to our students the history, facts and prominent figures of the War of the Independence, one of the historical processes most resorted to in the creation and consolidation of collective identities in Spain. To obtain a significant sample in our study, we use examples of the most representative publishing houses as well as texts studied in Secondary Education and published at different times in the last four decades.

Keywords: Secondary Education; Textbooks; Modern Age; Spanish War of the Independence; Identity.

¿Cómo han influido los avatares políticos de los últimos cuarenta años en la manera de transmitir la Guerra de la Independencia? ¿Qué visión de Napoleón se daba en las aulas españolas bajo el gobierno de Franco? ¿Cómo se habla de la aparición del liberalismo y las Cortes de Cádiz a los escolares de Cataluña? ¿Y a los de Madrid? ¿Ha evolucionado la visión sobre el Dos de mayo durante las últimas décadas? A esta y otras cuestiones intenta responder este trabajo.

Los manuales de Historia influyen en el imaginario individual del alumno, así como en la creación de una memoria colectiva y de unos estereotipos culturales Pueden contribuir a estigmatizar una época o a un personaje histórico, o bien a ensalzar para siempre la figura de un determinado monarca o grupo social. Partiendo de la convicción de que el libro de texto ha sido el recurso didáctico más utilizado para el desarrollo de la asignatura de Historia, resulta muy interesante prestar atención a la manera en que estos libros han presentado a nuestros escolares la historia, hechos y personajes de la Guerra de la Independencia, al ser esta uno de los procesos históricos más utilizados en la creación y consolidación de identidades colectivas. En él se reflejan los valores, estereotipos e ideologías de la sociedad que lo produce, y podemos examinar el currículo 
educativo de cada época. ${ }^{1}$ Los manuales son utilizados como síntesis del saber académico de cada materia y como fuente de evaluación, y ayudan a construir el imaginario individual y colectivo de futuras generaciones, al privilegiar u omitir ciertos valores dentro de los conocimientos en ellos transmitidos. $^{2}$

\section{ESTADO DE LA CUESTIÓN}

La construcción de conceptos y elementos que centren el contenido relacional y polivalente de la Didáctica de la Historia es uno de los cinco ámbitos de investigación de las Didáctica de las Ciencias Sociales planteados por Joaquín Prats y Rafael Valls. Dentro de este campo se incluye el estudio de los recursos didácticos, como es el caso de los libros de texto. ${ }^{3}$ En las últimas dos décadas se han realizado notables investigaciones en el análisis cuantitativo y cualitativo de la idoneidad de los contenidos plasmados en los libros de texto de Educación Primaria y Secundaria al vaivén de los distintos currículos, en especial son destacables los múltiples trabajos de Joan Pagès y Rafael Valls. ${ }^{4}$ Una gran parte de estos estudios han hecho hincapié en la adquisición de competencias básicas

\footnotetext{
1 Juan Esteban Rodríguez Garrido, Trato y maltrato de la Historia de España en los libros de texto. Desde 1970 hasta nuestros días (Madrid: Editorial Académica Española, 2012).

2 María Montserrat León Guerrero, «Evolución de la Geografía y la Historia en los libros escolares», en Una mirada al pasado y un proyecto de futuro. Investigación e innovación en didáctica de las ciencias sociales, eds. Joan Pagès i Blanch y Antoni Santisteban Fernández (Barcelona: Universitat Autónoma de Barcelona, 2013), 78.

3 Joaquín Prats y Rafael Valls, «La Didáctica de la Historia en España: estado reciente de la cuestión», Didáctica de las Ciencias Experimentales y Sociales, 25 (2011): 17-35.

${ }^{4}$ Entre otros títulos relacionados con los libros de texto de Joan Pagès destacan «Líneas de investigación en didáctica de las ciencias sociales», en Enseñar y aprender Ciencias Sociales, Geografía e Historia en la educación secundaria, coords. Pilar Benejam y Joan Pagès (Barcelona: ICE de la Universidad de Barcelona, Horsori, 1997), 209-226; «Enseñar a enseñar Historia: la formación didáctica de los futuros profesores de Historia», en Miradas a la Historia. Reflexiones historiográficas en recuerdo de Miguel Rodríguez Llopis, coords. María Encarna Nicolás Marín y José Antonio Gómez Hernández (Murcia: 2004), 155-178. De Rafael Valls, entre otros, Enseñanza de la Historia y textos escolares (Buenos Aires: Libros del Zorzal, 2008) y «La enseñanza de la Historia: entre polémicas interesadas y problemas reales Didáctica de la Historia en España: estado reciente de la cuestión», en Miradas a la Historia, 141-154, donde marcaba la desigual formación historiográfica y didáctica del profesorado de Secundaria en detrimento de la segunda, y junto a Nicolás Martínez y Francisco Pineda, «El uso del libro de texto en Historia de España en Bachillerato: diez años de estudio (1993-2003) y dos reformas (LGE-LOGSE)», Didáctica de las Ciencias Experimentales y Sociales, 23 (2009): 3-35.
} 
y del pensamiento histórico en los alumnos. ${ }^{5}$ También es reseñable el desarrollo de varios encuentros monográficos sobre esta temática, tanto ciclos de conferencias como revistas científicas. ${ }^{6}$

Actualmente, los libros de textos podrían cumplir una función más significativa dentro de las aulas incorporando fines y objetivos educativos que faciliten el trabajo en las diferentes materias. Esta herramienta didáctica debe cumplir con cuatro grandes fines del proceso de enseñanza-aprendizaje de la historia propuestos por Joaquín Prats y Joan Santacana en 2011: facilitar la comprensión del presente, contribuir al desarrollo de las facultades intelectuales, enriquecer otros temas del currículo y, por último, ayudar a adquirir sensibilidad social, estética, científica, etc.. ${ }^{7}$

Es indudable que los libros de texto pueden presentar un sesgo político afín a los grupos de comunicación a los que pertenecen las editoriales y tienen un evidente objetivo económico, aunque deben ayudar al aprendizaje de unos contenidos históricos que permitan desarrollar a los estudiantes un espíritu crítico. Algunos autores de textos escolares han creado héroes de todos los personajes históricos, encontrando una narrativa maestra, encajando todos los eventos desde una visión general de la historia. De esta manera, como exponen Carretero y Sartri, los libros de texto colaboran en la construcción de la memoria colectiva desde el ámbito escolar posibilitando la conformación y mantenimiento de identidades homogéneas en grupos heterogéneos. ${ }^{8}$

\footnotetext{
${ }^{5}$ Jorge Sáiz Serrano, «Alfabetización histórica y competencias básicas en libros de texto de Historia y en aprendizajes de estudiantes», Didáctica de las Ciencias Experimentales y Sociales, 27 (2013), 43-66, y «Fuentes históricas y libros de texto en secundaria: una oportunidad perdida para enseñar competencias de pensamiento histórico», Ensayos. Revista de Educación de la Facultad de Albacete, 29-1 (2014): 83-99.

${ }^{6}$ Luis Arranz Márquez (coord.), Actas del 5. ${ }^{\circ}$ Congreso sobre el libro de texto y materiales didácticos (Madrid: Universidad Complutense, 1997), y los monográficos Los libros de texto. Revista Iber. Didáctica de las ciencias sociales, geografía e historia, 70 (2011) y Ensayos. Revista de la Facultad de Educación de Albacete, 29 (1), (2014).

${ }^{7}$ Rodrigo Salazar Jiménez, María Carmen Rojo Ariza y Virginia Gámez Ceruelo, «La Segunda República y la Guerra Civil española según los libros de texto de Cataluña a inicios del siglo XXI», en Una mirada al pasado y un proyecto de futuro. Investigación e innovación en didáctica de las ciencias sociales, eds. Joan Pagès i Blanch y Antoni Santisteban Fernández (Barcelona: Universitat Autònoma de Barcelona, 2014), vol. 2, 150. El trabajo mencionado es de Joaquín Prats y Joan Santacana, «Trabajar con fuentes materiales en la enseñanza de la historia», en Geografía e Historia: investigación, innovación y buenas prácticas, coord. Joaquín Prats (Barcelona: Graó, 2011), 11-37.

${ }^{8}$ Salazar Jiménez, Rojo Ariza y Gámez Ceruelo, «La Segunda República y la Guerra Civil española según los libros de texto...», 151.
} 
Prats señalaba que la enseñanza de la historia en Educación Secundaria no debía recurrir a acontecimientos episódicos y efemérides históricas que pretendieran justificar ideas o legitimar realidades políticas actuales. ${ }^{9}$ Algunos autores han destacado cómo los mitos históricos o el ensalzamiento de los «hechos diferenciales» generan distorsión de la realidad social o legitiman situaciones de poder de reivindicaciones nacionalistas. La historiografía decimonónica gestó gran parte de esos argumentos que recogían la esencia del pueblo español que le confiere una capacidad de evolución desde un sustrato primitivo que forja una personalidad, hilada en el devenir cronológico de las distintas etapas divididas por reinados. También ha de considerarse cómo el recurso al envejecimiento del presente planteó un impulso a desarrollar legitimaciones historicistas de las comunidades autónomas que deforman la realidad, con el fin de rescatar identidades regionales pretéritas, cuando a veces prevalecen más los criterios geográficos o económicos que los históricos o culturales. ${ }^{10}$

En el presente trabajo se hace evidente que las distintas circunstancias políticas por las que ha ido pasando España desde 1970, así como la propia evolución en el modo de hacer y estudiar la Historia, han traído consigo importantes cambios en la manera de presentar y estudiar cuestiones como la Guerra de la Independencia y sus principales protagonistas.

\section{CRITERIOS METODOLÓGICOS}

Para la delimitación de la investigación hemos atendido a un triple criterio metodológico:

1. Temporal. La acotación temporal en la elección de los textos a analizar es evidentemente necesaria. Así, hemos considerado la década de los setenta para poner principio a esa elección de textos: a nadie escapa el significado de esas fechas pues corresponden a la promulga-

\footnotetext{
9 Joaquín Prats Cuevas, «Dificultades para la enseñanza de la Historia en la Educación Secundaria: reflexiones ante la situación española», Revista de Teoría y Didáctica de las Ciencias Sociales, 5 (2001): 71-98 (78-80).

${ }^{10}$ Dentro de la obra colectiva coordinada por Juan Sisinio Pérez Garzón, La gestión de la memoria. La Historia de España al servicio del poder (Barcelona: Crítica, 2000) interesan en este marco las reflexiones de Eduardo Manzano Moreno, «La construcción del pasado nacional», 48-61, Juan Sisinio Pérez Garzón, «La creación de la Historia de España», 96-108, y Aurora Rivière Gómez, «Envejecimiento del presente y dramatización del pasado. Una aproximación a las síntesis históricas de las Comunidades Autónomas españolas (1975-1995)», 161-219.
} 
ción de la Ley General de Educación de 1970, también llamada «ley Palasí». Y con ejemplos de las sucesivas leyes orgánicas educativas, como la denominada LOGSE (1990), elaborada desde el gobierno por el PSOE, la LOCE o Ley Orgánica de Calidad de la Enseñanza (2002), promovida por el gobierno del PP, la LOE (2006) y la LOMCE (2013). Creemos que los acontecimientos políticos y sociales que se desarrollan en España durante los más de treinta años que separan ambas fechas (muerte del general Franco, subida al trono del rey Juan Carlos I, democratización del país, aprobación de una nueva Constitución, configuración del nuevo Estado de las Autonomías, llegada al poder del PSOE, integración de España en la Unión Europea, gobiernos del PP, etc.) tienen una influencia importante en el desarrollo de las políticas educativas y, por extensión, en el modo de transmitir conocimientos desde los manuales escolares.

2. Comercial. Acudimos a aquellas editoriales que cubrían y cubren la mayor parte de la cuota del mercado; es decir, que producen los manuales más extendidos y usados por las escuelas y alumnos de toda España. El estudio se centra en las siguientes cuatro editoriales: Santillana, Anaya, SM y Edelvives. Cuatro editoriales que cubrían en torno al 65 por ciento del mercado de libros escolares en España en 1976 y cuyo peso fue en aumento. Para hacer estas estimaciones se han considerado dos documentos de características diferentes. El más lejano en el tiempo (1976) se basa en una encuesta realizada al profesorado de Educación General Básica (EGB)y los dato que contiene son sólo de este nivel educativo; el segundo (1995) contiene los datos estadísticos hechos públicos por el Ministerio de Educación y Cultura referidos a toda la producción editorial relacionada con el sector de la enseñanza y educación. En 1976, la frecuencia de uso de las editoriales, según el propio profesorado de la EGB, era la siguiente: Anaya (28\%), Santillana (13\%), SM (11\%), Edelvives (10\%), Álvarez (10\%), Hermanos de Santiago Rodríguez (5\%), Magisterio Español (4\%), Teide $(3 \%)$, Vicens Vives $(2 \%)$ y otras editoriales $(10 \%)$. 


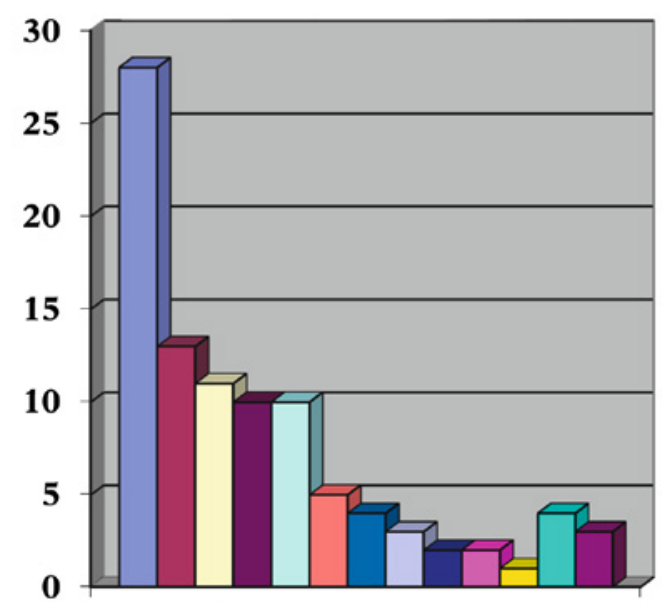

Porcentaje ventas

\begin{tabular}{|l|}
\hline$\square$ Anaya \\
$\square$ Santillana \\
$\square$ SM \\
$\square$ Edelvives \\
$\square$ Álvarez \\
$\square$ H. de S.Rguez. \\
$\square$ Magisterio E. \\
$\square$ Teide \\
$\square$ Vicens Vives \\
$\square$ Casals \\
$\square$ Bruño \\
$\square$ Otras
\end{tabular}

Figura 1. Editoriales ordenadas por el número de libros aprobados por el MEC en 1995.

La relación de las 10 mayores editoriales ordenadas de mayor a menor número de ISBN aprobados de libros de enseñanza y educación en el año 1995 es la siguiente: ${ }^{11}$

1. Grupo Anaya.

2. Santillana.

3. SM.

4. Luis Vives (Edelvives).

5. Vicens Vives.

6. Bruño.

7. Barcanova.

8. Ministerio de Educación y Ciencia.

9. Universidad Nacional de Educación a Distancia.

10. Everest.

11 MEC, Panorámica de la edición española de libros 1995 (Ministerio de Educación y Cultura, 1996), 150. 
A la luz de estos datos encontramos una posición predominante en el mercado editorial de las cuatro editoriales referidas, posición que justifica la especial concentración en ellas para la realización de este estudio.

3. Temático. Pocos acontecimientos como la Guerra de la Independencia marcan tan claramente un antes y un después en la historia de un país. Tanto es así que habitualmente se considera que con este proceso comienza la Edad Contemporánea en España. Nos parece, además, que es uno de esos acontecimientos especialmente interesantes para entender el tipo de Historia que se quiere transmitir en cada momento político y social por los que hemos atravesado en las últimas décadas. El concepto que los diferentes gobiernos han tenido sobre la identidad histórica de España se refleja nítidamente en cómo se han transmitido a nuestros escolares determinados aspectos de nuestra historia común. La Guerra de la Independencia es, sin duda, uno de los más destacados.

\section{EDICIONES ANAYA}

\section{Ciencias Sociales. 8. ${ }^{\circ}$ EGB (1975-1984)}

Mariano Mañero Monedo, Domingo J. Sánchez Zurro e Isidoro González Gallego son los autores de este manual de Anaya, que sería el utilizado por los escolares de 13-14 años en la segunda mitad de los años setenta y primera mitad de los ochenta, con pequeñas modificaciones como el acortamiento de algún pie de foto en las ediciones más actuales o la introducción de actividades al final de cada tema.

La primera vez que en los contenidos aparece la historia española es en el tema 3 ( «La guerra de la Independencia»), del bloque 1 ( La Europa napoleónica»). ${ }^{12}$ A explicar la Guerra de la Independencia dedican los autores dos páginas. El porqué del levantamiento se explica de un modo

12 Mariano Mañero Monedo, Domingo J. Sánchez Zurro e Isidoro González Gallego, Ciencias Sociales. 8. ${ }^{\circ}$ EGB (Madrid: Anaya, 1975), 6-17. 
tradicional, en el que se pone énfasis en los abusos de los franceses y en el patriotismo que movió al pueblo a levantarse:

La Guerra de la Independencia supone la lucha del pueblo español por conservar su personalidad como nación.

Los atropellos de los soldados franceses y la marcha de la familia real a Bayona encendieron la cólera del pueblo y motivaron el levantamiento del 2 de mayo de 1808 en Madrid. ${ }^{13}$

A continuación, se narra el desarrollo de los acontecimientos bélicos, haciendo hincapié en el sistema de guerrillas que utilizaron los españoles y en el carácter popular de esta resistencia a los franceses pues el levantamiento había sido condenado por las autoridades. Asimismo, se hace una referencia elogiosa a la Constitución de Cádiz, unos elogios acompañados de cierta crítica a aquellos que no la aceptaron, calificados como escasamente preparados:

Los reformistas lograron aprobar la Constitución de 1812, que reconoce la soberanía nacional y las libertades individuales. $\mathrm{Ni}$ los absolutistas, ni la masa del pueblo español, escasamente preparada, aceptaron la Constitución. ${ }^{14}$

Algún autor ha utilizado el análisis de la Constitución de 1812 como secuencia didáctica en la que trabajar las repercusiones de la Guerra de la Independencia y la obra de Cádiz a escala local. ${ }^{15}$

En cuanto a los documentos gráficos del tema, este manual recoge abundancia de fotografías, retratos y mapas que acompañan siempre al texto, completándolo o clarificándolo. En este asunto en concreto, encontramos dos retratos (del guerrillero «El Empecinado» y del «afrancesado» Moratín), un mapa del desarrollo de la guerra, el cuadro de Francisco de Goya la «Carga de los mamelucos en la Puerta del Sol» y una imagen que representa una de las sesiones de las Cortes de Cádiz.

13 Mañero Monedo, Sánchez Zurro y González Gallego, Ciencias Sociales. 8. ${ }^{\circ}$ EGB, 12.

14 Mañero Monedo, Sánchez Zurro y González Gallego, Ciencias Sociales. 8. ${ }^{\circ}$ EGB, 13.

15 Diego Sobrino, «La enseñanza de la Constitución de Cádiz. Una experiencia en bachillerato desde la historia local», Iber. Didáctica de las Ciencias Sociales, Geografía e Historia, 72, (2012), 47-56. 


\section{Ciencias Sociales. 8. ${ }^{\circ}$ EGB (1985-1990)}

El equipo Aula 3 es el autor de este manual de Anaya para 8. ${ }^{\circ}$ de EGB. En el tema 5: «España pasa de la monarquía absoluta a la constitucional». ${ }^{16}$ En él se nos habla de la crisis del proyecto reformista borbónico, de la Guerra de la independencia, de los reinados de Fernando VII e Isabel II, del sexenio revolucionario y, por último, de la restauración de la monarquía en la persona de Alfonso XII. El primer epígrafe del tema aparece dedicado al reinado de Carlos IV y a sus hechos. Los autores nos presentan una visión negativa del reinado, personalizada fundamentalmente en la persona de Manuel Godoy: «Godoy gobernaba como un déspota autoritario y había llegado a suprimir festejos tan populares como los toros». ${ }^{17}$

Sin embargo, la caída de Godoy es presentada como una consecuencia de la oposición y las actitudes de las clases reaccionarias: nobleza, clero y la franja más inculta del pueblo, que se dejó llevar por las dos anteriores:

La nobleza, a la vista de lo que estaba pasando en Francia, teme perder sus privilegios. El clero, ve peligrar la religión ante la actuación de los revolucionarios de París, y el pueblo bajo, alentado por la nobleza y el clero, piensa que la nobleza y el clero, piensa que la influencia de los odiados franceses, que se han atrevido a matar a su rey, le hará perder las costumbres populares y sus tradiciones seculares.

Tras la abdicación de Carlos IV en su hijo Fernando VII llegamos a la Guerra de la Independencia, presentada, como es habitual, como un levantamiento patriótico contra unos ocupantes ilegítimos y un rey impuesto: José I. Lo vemos en las siguientes afirmaciones: «[...] los franceses se aprovecharon para ocupar la Península»o «imponer en el trono a José I, hermano del Emperador». ${ }^{18}$

Se narra luego, en escasas veinte líneas, la Guerra de la Independencia. Los autores se limitan a nombrar de pasada la heroicidad en la re-

\footnotetext{
16 Equipo Aula 3, Ciencias Sociales. 8. ${ }^{\circ}$ EGB (Madrid: Anaya, 1985), 70-87.

17 Equipo Aula 3, Ciencias Sociales. 8. ${ }^{\circ} \mathrm{EGB}, 72$.

18 Equipo Aula 3, Ciencias Sociales. 8. ${ }^{\circ} \mathrm{EGB}, 74$.
} 
sistencia de ciudades como Zaragoza y Gerona, el fenómeno de las «guerrillas», la existencia de los afrancesados y la importante ayuda de los ingleses al mando de Wellington.

Eso sí, en un cuadro aparte se da información complementaria sobre algunos de estos temas. Así, por ejemplo, se dedican unas líneas a hablar del Dos de mayo madrileño y de los capitanes Daoíz y Velarde, del Parque de Artillería de Monteleón. Asimismo, se nombran algunos «guerrilleros» como Espoz y Mina, el Empecinado, el Cura Merino, José Rumeu, el Charro, etc. También se habla de la defensa de Zaragoza por parte del general Palafox, Agustina de Aragón, el Tío Jorge o la Condesa de Buretta.

\section{Historia. 2. ${ }^{\circ}$ Ciclo ESO (1998)}

$\mathrm{Al}$ igual que otras grandes editoriales nacionales, Anaya decidió publicar ediciones autonómicas de sus libros de texto. Hemos investigado varias de las más representativas para, una vez más, comprobar en qué medida esta editorial transmite o no distintos contenidos según la región de España a la que vaya dirigida el manual. Hemos seleccionado títulos dirigidos al segundo ciclo de ESO, elaborados por el mismo equipo de profesores, formado por Joaquín Prats, José Emilio Castelló, María Camino García, Ignacio Izuzquiza, María Antonia Loste y Montserrat Pongiluppi. Este equipo se irá complementando con distintos nombres según la edición autonómica que analicemos. En resumidas cuentas: un tronco común, la editorial Anaya y la mayor parte de los contenidos, del que emanan distintas ramas autonómicas con algunos contenidos concretos elaborados por profesores que sólo intervienen en la edición en cuestión.

Los cambios temáticos más significativos están relacionados con la disminución de héroes y grandes personajes, y sus hazañas, prioritariamente bélicas, que han reducido enormemente su presencia, con la excepción de los representantes de la monarquía, que se han seguido mantenido. ${ }^{19}$

${ }^{19}$ León Guerrero, «Evolución de la Geografía y la Historia», 77-84. 
Procedemos a analizar los manuales de Anaya en su edición del segundo ciclo de la ESO de 1998 para Madrid, País Vasco, Navarra y Andalucía. Vamos a comprobar si los escolares de estas comunidades reciben la misma información o, por el contrario, ésta se transforma en base a los intereses regionales de los distintos gobernantes, así como los posibles intereses económicos de la propia editorial.

Del total de diecisiete temas que ofrece el manual, son siete los que vamos a revisar pues son éstos los dedicados a Historia de España, concretamente desde los Reyes Católicos al siglo xx. Tras revisar cuidadosamente — página a página de cada manual, actividad por actividad y foto por foto- la primera conclusión es la siguiente: las distintas ediciones autonómicas son idénticas salvo en un pequeño epígrafe particular que se incluye en cada tema y que explica la situación del territorio concreto durante la época estudiada. Esa es la única diferencia: los contenidos generales son comunes pero cada edición tiene, en las distintas unidades, alguna página (siempre en el mismo número en unas y otras ediciones) enfocada a las cuestiones regionales.

Turno para analizar los contenidos del tema 10: «La instauración del liberalismo en España». ${ }^{20}$ Lo primero que llama la atención es el escaso espacio que se le dedica a un hecho habitualmente alabado y analizado a fondo desde el orgullo patriótico: la Guerra de la Independencia contra Francia. En un epígrafe formado por cuatro pequeños párrafos que suman un total de diecinueve líneas se explican, con un tono muy neutro, los hechos, en otro tiempo narrados como gloriosos por esta misma editorial. Aquellos nombres míticos y ensalzados, El Empecinado, Espoz y Mina, Palafox, Castaños y tantos otros, antaño permanentemente presentes en los manuales escolares han desaparecido. Lo mismo cabe decir de aquellos detallados mapas que representaban el desarrollo del conflicto, sus batallas más importantes, las victorias más gloriosas de las Armas Españolas. Todo ha quedado reducido a diecinueve líneas que se limitan a exponer someramente la cuestión, sin mayores pretensiones patrióticas. 20 Joaquín Prats, José Emilio Castelló, María Camino García, Ignacio Izuzquiza, María Antonia Loste
y Montserrat Pongiluppi, Historia. 2. $^{\circ}$ ciclo ESO (Madrid: Anaya, 1998), 166-183. 
Por otra parte, el manual es, desde luego, un producto de la implantación de nuevas corrientes historiográficas en los libros de texto. Los cambios historiográficos y su relación con la didáctica de la Historia han quedado recogidos en el trabajo monográfico de Miralles, Molina y Ortuño, en el que se defiende la importancia de adecuar ambas disciplinas a los niveles educativos de Secundaria y Bachillerato. ${ }^{21}$ Tanto en la forma de exponer los contenidos como en el fondo de los mismos, se aprecian cambios ostensibles. La progresiva disminución de los importantes nombres propios de nuestra historia; el aumento, por el contrario de las líneas dedicadas a cuestiones al margen de la historia propiamente política o militar, tales como la economía y la sociedad son elementos habituales en los libros de texto de los noventa.

\section{Historia. Ciencias Sociales $4 .^{\circ}$ ESO (2014)}

Manuel Burgos Alonso y María Concepción Muñoz-Delgado y Mérida son los autores de este manual de Anaya que recoge los contenidos de la LOMCE, la última normativa educativa que entró en vigor en 2014. ${ }^{22}$ Dentro de la doble página «El inicio de la crisis política» y tras la explicación del reinado de Carlos IV, el segundo epígrafe aborda el conflicto bélico entre españoles y franceses bajo el título "Guerra y revolución (1808-1814)», en el que se sugiere que la guerra creó tres grupos ideológicos: afrancesados, absolutistas y liberales. Además, se mencionan de forma sucinta las principales contiendas bélicas (Bailén, Arapiles) acompañadas de un mapa con el desarrollo de los episodios. Finalmente, se enuncia el último epígrafe como «Las Cortes de Cádiz» en el que se enuncia el diseño del nuevo Estado reflejado en la Constitución de 1812. Este documento aparece en la doble página inicial para introducir el tema, donde queda caracterizado por su breve vigencia y por la influencia en la redacción de las primeras constituciones latinoamericanas.

\footnotetext{
21 Pedro Miralles, Sebastián Molina y Jorge Ortuño, La importancia de la historiografía en la enseñanza de la historia (Granada: Grupo Editorial Universitario, 2011).

22 Manuel Burgos Alonso y María Concepción Muñoz-Delgado y Mérida, Historia. Ciencias Sociales 4. ${ }^{\circ}$ ESO (Madrid: Anaya, 2014).
} 


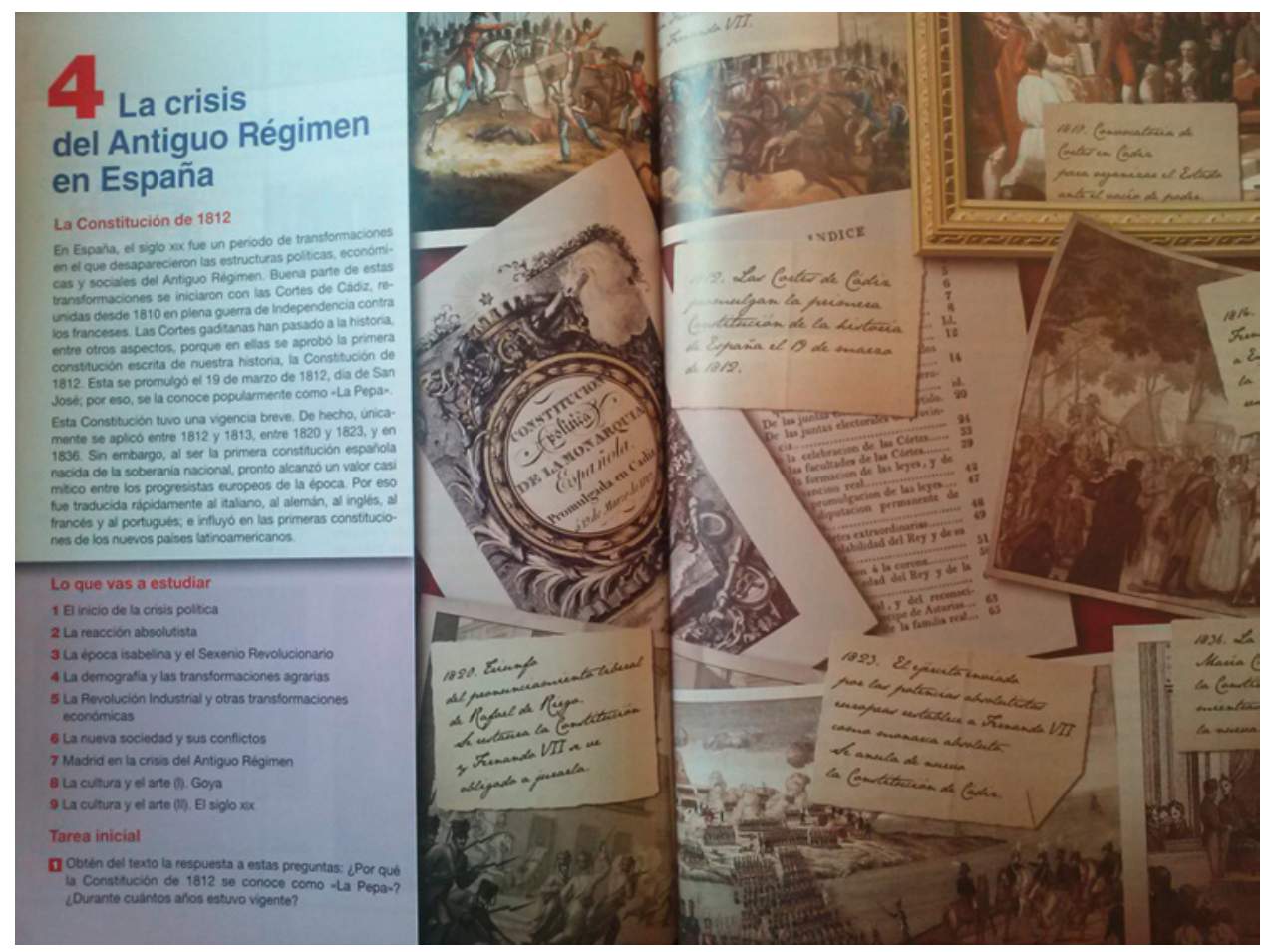

Figura 2. Historia. Ciencias Sociales, Anaya, 4. ${ }^{\circ}$ ESO (2014)

Unas páginas más adelante, en el apartado autonómico «Madrid en la crisis del Antiguo Régimen», se mencionan algunas consecuencias económicas y demográficas de la guerra:

La guerra tuvo efectos devastadores en nuestra región: crisis de subsistencia en 1812, muerte de unas 20000 personas y destrucción del Palacio del Buen Retiro y de la Real Fábrica de Porcelanas.

En esta doble página autonomizada se recoge en un cuadro explicativo la participación de la ciudad de Madrid en la guerra en la defensa del Parque de Artillería de Monteleón (actual Plaza del Dos de Mayo), con la heroica participación y resistencia de los del capitán Luis Daoíz y su subalterno Pedro Velarde. Es reseñable cómo siendo el libro de texto más actual analizado, recoge cierto espíritu añejo de los manuales de los años setenta y ochenta en los que se ensalzaban algunas de las hazañas del conflicto bélico con los franceses, aunque se muestra en forma de fuente primaria para realizar una adecuada contextualización histórica. 


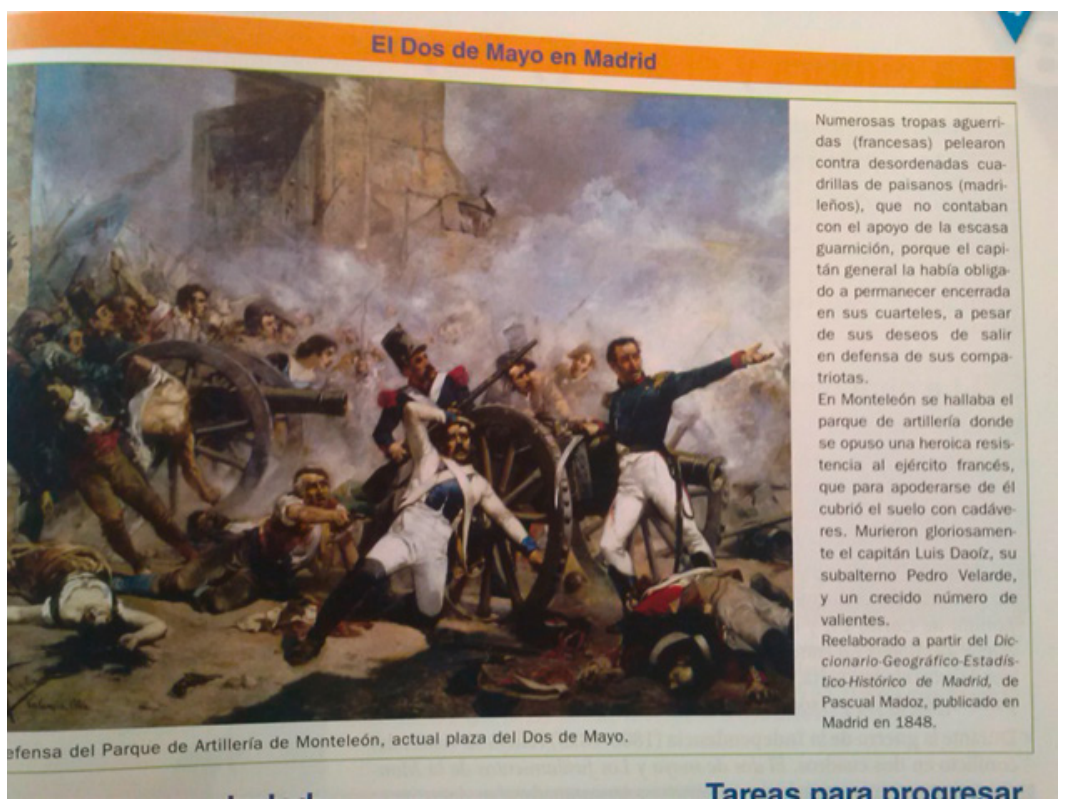

Figura 3. Historia. Ciencias Sociales, Anaya, $4 .^{\circ}$ ESO (2014)

\section{EDITORIAL EDELVIVES}

\section{Mundo contemporáneo $8 .^{\circ}$ EGB (1974-1981)}

Es un manual de Historia Universal cuya autoría corresponde a Carlos Campoy García, M. ${ }^{a}$ del Carmen Gutiérrez Ruiz y Joaquín Moreno. Formado por un total de 38 temas, de los cuales serán once los que nos hablen de Historia de España, para explicar el siglo XIX, el tema 13 («Guerra, revolución y reacción en España») ${ }^{23}$ comienza con la Guerra de la Independencia, acontecimiento que, al modo más tradicional, es presentado de la manera más patriótica posible:

Una de las gestas más importantes del pueblo, cuyo significado no puede entenderse como una simple guerra civil. La guerra de la Independencia fue la lucha de los españoles contra los franceses invasores a los que consiguió expulsar, sin contar con armas, apoyos, dinero, ni un poder organizado. ${ }^{24}$

\footnotetext{
${ }^{23}$ Carlos Campoy García, María del Carmen Gutiérrez Ruiz y Joaquín Moreno, Mundo contemporáneo. 8. ${ }^{\circ}$ EGB (Zaragoza: Edelvives, 1974), 116-124.

${ }^{24}$ Campoy García, Gutiérrez Ruiz y Moreno, Mundo contemporáneo. 8. ${ }^{\circ}$ EGB, 117.
} 
Por supuesto se habla de la jornada del Dos de mayo en Madrid y se destaca como héroes nacionales a Daoíz, Velarde y Manuela Malasaña. Se habla, asimismo, del sistema de «guerrillas» con el que los españoles se opusieron a los franceses:

Las guerrillas se organizaban espontáneamente y entraban a formar en las partidas gentes de toda condición y clase social. Lo mismo los aristócratas que la burguesía, los intelectuales, los campesinos, el clero y los artesanos..., todos se sintieron atraídos por la gran empresa de impedir el secuestro de España por parte de Napoleón. ${ }^{25}$

Lógicamente, se dedica bastante espacio a hablar de las Cortes reunidas en Cádiz de 1810 a 1812 y de las reformas llevadas a cabo por éstas: aprobación de una Constitución, separación de poderes, división de España en provincias, centralismo administrativo, ruptura del orden estamental, supresión de los señoríos, declaración de igualdad de todos los españoles ante la ley, supresión de los gremios, triunfo del librecambismo, apertura al capitalismo, etc. Todas estas reformas las juzgan los autores de la siguiente manera:

Los españoles vieron con sorpresa la profunda transformación que realizaron las Cortes de Cádiz, que equivalía a conseguir, sin sangre, los resultados de la Revolución Francesa.

\section{Historia. 4. ${ }^{\circ}$ ESO (2003)}

Manuel Peña Vílchez, Dolores Quesada Nieto, M. ${ }^{a}$ Isabel Ruiz Rodríguez y Juan Francisco Valenzuela Villén elaboraron, bajo la asesoría técnica y pedagógica de Luis Arranz Márquez, el siguiente manual de la editorial Edelvives para alumnos de $4 .^{\circ}$ de la ESO. El libro abarca, tal y como corresponde a ese nivel, desde los siglos XVI al XX, es decir, en el caso de España, desde los Reyes Católicos a la llamada «España democrática».

Catorce temas conforman el manual, todos ellos dedicados a Historia, aunque con un barniz de economía y sociedad y frecuentes epígrafes

${ }^{25}$ Campoy García, Gutiérrez Ruiz y Moreno, Mundo contemporáneo. 8. ${ }^{\circ}$ EGB, 118. 
dedicados a la Historia del Arte. El tema 7 («España en el siglo XIX») ${ }^{26}$ se dedica en exclusiva a la Historia de España. Se inicia un tema con la llamada "crisis del Antiguo Régimen», epígrafe en el que se alude, muy levemente a los últimos hechos del reinado de Carlos IV, principalmente a aquellos que llevaron a la ocupación francesa de la península. A Godoy se le nombra poco, la principal referencia a este personaje se hace a través de una foto, al pie de la cual podemos leer el siguiente juicio:

Godoy, extremeño de una familia ilustre venida a menos, contó con el apoyo político de la reina María Luisa. Procuró la alianza con Francia frente a Gran Bretaña, pero se equivocó. El motín de Aranjuez significó su caída y en 1808 se exilió a Francia. ${ }^{27}$

A continuación se dedica una página a narrar la Guerra de la Independencia. El tono patriótico y triunfalista de ediciones anteriores se atempera en la actual, no obstante no desaparece el término «ocupación extranjera», ni las alusiones a guerrilleros como el Empecinado, el cura Merino o Espoz y Mina. En cualquier caso, el 80 por ciento del espacio lo dedican los autores a explicar las distintas fases de la guerra, acompañando la explicación con un mapa que muestra, mediante flechas de colores, los movimientos de los distintos ejércitos. Así pues, no se renuncia a cierta identidad patriótica en la narración del conflicto, pero acudiendo a los párrafos literales comprobamos cómo ha cambiado el tono general:

Una de las gestas más importantes del pueblo, cuyo significado no puede entenderse como una simple guerra civil. La guerra de la Independencia fue la lucha de los españoles contra los franceses invasores a los que consiguió expulsar, sin contar con armas, apoyos, dinero, ni un poder organizado.

El 2 de mayo de 1808, el pueblo de Madrid, con la ayuda de los capitanes de artillería Daoiz y Velarde y el teniente Ruiz, se levantaron contra la ocupación extranjera. ${ }^{28}$

\footnotetext{
${ }^{26}$ Manuel Peña Vílchez, Dolores Quesada Nieto, María Isabel Ruiz Rodríguez y Juan Francisco Valenzuela Villén, Historia. $4{ }^{\circ}$ ESO (Madrid: Edelvives, 2003), 106-123.

27 Peña Vílchez, Quesada Nieto, Ruiz Rodríguez y Valenzuela Villén, Historia. 4. ${ }^{\circ}$ ESO, 108.

28 Campoy García, Gutiérrez Ruiz y J. Moreno, Mundo contemporáneo. $8 .^{\circ}$ EGB, 117 y Peña Vílchez, Quesada Nieto, Ruiz Rodríguez y Valenzuela Villén, Historia. $4 .^{\circ}$ ESO, 109.
} 
Como vemos, el primer párrafo se muestra bajo un sesgo más épico ( $\sin$ armas, ni apoyo, ni dinero...), al ensalzar el mérito militar de la victoria frente a los franceses. Respecto a las guerrillas ocurre algo similar:

Las guerrillas se organizaban espontáneamente y entraban a formar en las partidas gentes de toda condición y clase social. Lo mismo los aristócratas que la burguesía, los intelectuales, los campesinos, el clero y los artesanos..., todos se sintieron atraídos por la gran empresa de impedir el secuestro de España por parte de Napoleón.

Las guerrillas fueron partidas formadas generalmente por campesinos, buenos conocedores del terreno, que atacaban con rapidez a los franceses, dificultando las comunicaciones o asediando cuarteles. Estaban dirigidas por jefes audaces y enérgicos que fueron muy queridos por el pueblo. ${ }^{29}$

El cambio de tono es evidente para cualquier lector, expresiones como «la gran empresa de impedir el secuestro de España por parte de Napoleón» parecen imposibles de encontrar en cualquier manual actual.

\section{EDITORIAL SANTILLANA}

\section{Ciencias Sociales 8. ${ }^{\circ}$ EGB (1973-1977)}

Julián Abad, Enrique Centeno, Eduardo Chamorro, Rosario de la Iglesia, José María Parra y Ángel Sánchez-Gijón, bajo la dirección de Emilio Sánchez Lázaro y Sergio Sánchez fueron los autores de este manual que Santillana elaboró para los escolares de $8 .^{\circ}$ de EGB de la segunda mitad de los setenta, bajo los postulados e indicaciones de la Ley General de Educación de 1970.

La Guerra de la Independencia aparece tratado de forma completa en el tema 19, titulado «El pueblo frente a Napoleón». ${ }^{30}$ Se hace un recorrido muy patriótico por la Historia del conflicto y no se dejará de nombrar

\footnotetext{
${ }^{29}$ Campoy García, Gutiérrez Ruiz y Moreno, Mundo contemporáneo. $8^{\circ}$ EGB, 118 y Peña Vílchez, Quesada Nieto, Ruiz Rodríguez y Valenzuela Villén, Historia. $4 .^{\circ}$ ESO, 109.

${ }^{30}$ Emilio Sánchez Lázaro, Sergio Sánchez, Julián Abad, Enrique Centeno, Eduardo Chamorro, Rosario de la Iglesia, José María Parra y Ángel Sánchez-Gijón, Ciencias Sociales. 8. ${ }^{\circ}$ EGB (Madrid: Santillana, 1973), 344-356.
} 
a ninguno de los héroes populares de la contienda madrileña del Dos de mayo. Héroes que, según expone el manual, provenían del pueblo más llano:

Antonio Romero, esquilador de mulas; Antonio Sierra, mozo de pala de tahona; Antonio de Rivacoba, profesor de cirugía; Baltasar Ruiz, arriero; Bernardino Gómez, cerrajero; Domingo Braña, empleado; Francisco Martínez Valenti, abogado de los Reales Consejos; Félix Monje, guardacoches; Francisco López, del comercio de lencería; José Rodríguez, botillero, etc.. ${ }^{31}$

En todo momento, a José I se le califica de «rey intruso»y, asimismo, vemos como se critica, aunque de forma condescendiente, a los llamados «afrancesados»:

Fueron aborrecidos por el pueblo español, que estaba dando generosamente su sangre en una guerra sin precedentes. Su error estuvo en no haber comprendido que en la guerra de la Independencia, España se jugaba algo más que un cambio de dinastía $[\ldots]$ ¡Triste destino el de estos españoles que no supieron comprender el momento histórico que les tocó vivir!. ${ }^{32}$

De todas formas, más allá de considerarlo un intruso, la imagen que se da de José I no es negativa:

José I no carecía de buena voluntad ni de dotes de gobernante, y estaba animado de los mejores deseos hacia el pueblo español, pero su condición de rey intruso le ganó la antipatía y el odio del pueblo. $^{33}$

En los siguientes epígrafes se cuenta el desarrollo de la guerra en sí, así como el modo de los españoles de organizar la resistencia a los franceses: las guerrillas, el sitio y la batalla en campo abierto. Se destacan hechos heroicos de la guerra como la victoria de Bailén por parte del General Castaños, las resistencias de los sitios de Zaragoza y Gerona y las

\footnotetext{
31 Sánchez Lázaro et al., Ciencias Sociales. 8. ${ }^{\circ}$ EGB, 345.

32 Sánchez Lázaro et al., Ciencias Sociales. 8. ${ }^{\circ}$ EGB, 46.

33 Sánchez Lázaro et al., Ciencias Sociales. 8. ${ }^{\circ}$ EGB, 347.
} 
victorias de Albuera, Ciudad Rodrigo (enero de 1812), Los Arapiles (julio de 1812), Vitoria (junio de 1813) y San Marcial (agosto de 1813). Episodios todos ellos que, oportunamente recordados, contribuyen a fortificar el orgullo colectivo de la historia nacional, a consolidar el patriotismo. Un patriotismo puesto de manifiesto en escritos como el sitio de Gerona:

Durante siete meses Gerona resistió el ataque de 50.000 franceses. Álvarez de Castro, enfermo, se hacía llevar en camilla a los puestos de mayor peligro. A uno de sus oficiales que le preguntó a dónde podía retirarse le contestó: «al cementerio». ${ }^{34}$

Se dedican fotos a héroes nacionales como Agustina de Aragón, el cura Merino o «El Empecinado». A éste último se le elogió con un perfil de que extraemos las siguientes palabras:

Era el primero en el combate y el último en la retirada. Fue siempre magnánimo con los prisioneros y respetó sus vidas. Hasta sus mismos enemigos le admiraban.

El manual procura no dejar de nombrar a ninguno de los más famosos guerrilleros españoles:

Los guerrilleros españoles fueron la pesadilla del ejército francés. Sus jefes más famosos fueron Mariano Renovales y Miguel Sarasa, en Aragón; Juan Martín Díaz El Empecinado, el cura Merino, Francisco Sánchez Francisquete, el cura Quero, Fray Juan de Deliva El Capuchino, en las dos Castillas, León y Extremadura y, en Navarra, Mina El Mozo y Espoz y Mina. Jefes audaces y valientes hasta la temeridad, hicieron una guerra cruel y despiadada a los franceses, quienes respondieron con atroces represalias contra los guerrilleros y la población civil que les apoyaba o no les denunciaba. ${ }^{35}$

Las Cortes de Cádiz también son abordadas con profusión en el tema. Se habla de las distintas tendencias políticas dentro de las mismas, así como de su labor legislativa, de entre la que se destaca la Constitución

${ }^{34}$ Sánchez Lázaro et al., Ciencias Sociales. 8. ${ }^{\circ}$ EGB, 349.

${ }^{35}$ Sánchez Lázaro et al., Ciencias Sociales. 8. ${ }^{\circ}$ EGB, 351. 
de 1812, que proclamaba la soberanía nacional frente a la soberanía absoluta del rey:

Los principales puntos de la Constitución de 1812 son los siguientes: la soberanía nacional reside en la nación española; el catolicismo es la única religión de España; la monarquía es hereditaria pero no absoluta; el rey ve sus poderes limitados por la Constitución, que debe jurar; se proclama el principio de la división de los tres poderes del Estado: legislativo, ejecutivo y judicial; y establece los derechos y deberes de los ciudadanos. ${ }^{36}$

Por último, se habla de las consecuencias de la guerra, una catástrofe en todos los aspectos que trajo consigo una España desolada en lo material y en lo moral:

Todos los progresos obtenidos en el siglo XVIII en la agricultura, la industria y el comercio quedaron borrados de golpe por seis años de devastaciones materiales.

\section{Sociedad 80, 8. ${ }^{\circ}$ EGB (1984-1987)}

Pablo Castejón, José Luis Díez y Jaime Mascaró son los autores de este manual editado por Santillana en 1984 para el 8. ${ }^{\circ}$ curso de la EGB. Es un libro dedicado casi enteramente a la Historia, al contrario que otros de niveles anteriores, que incluían también temas de geografía y economía. El manual abarca tres siglos, XVIII, XIX y XX, desde la época de la Ilustración a la España de la Constitución.

De este manual nos interesa el tema 5 ( $\mathrm{El}$ reinado de Carlos IV y la Guerra de la Independencia»). ${ }^{37}$ Los autores presentan a un monarca de débil carácter, que deja los asuntos de gobierno en manos ajenas, las de Manuel Godoy:

era bondadoso, pero de débil carácter; se dejó dominar por su esposa, María Luisa de Parma, y, más que a los asuntos de Esta-

\footnotetext{
36 Sánchez Lázaro et al., Ciencias Sociales. 8. ${ }^{\circ}$ EGB, 354.

37 Pablo Castejón, José Luis Díez y Jaime Mascaró, Sociedad 80. 8. ${ }^{\circ}$ EGB (Madrid: Santillana, 1984), 40-47.
} 
do, este rey dedicó su tiempo a la caza y a su gran afición que era coleccionar aparatos mecánicos y relojes. ${ }^{38}$

Sobre todo en el tema se habla del levantamiento del Dos de mayo de 1808 y de la posterior Guerra de la Independencia, desarrollada hasta 1814. Se explican el motín de Aranjuez, las abdicaciones de Bayona y, por fin, el levantamiento del Dos de Mayo que trajo, como consecuencia la guerra. De la guerra, se nombran batallas épicas (como las de Bailén, Arapiles, Vitoria o San Marcial) y nombres legendarios, como Agustina de Aragón, el general Palafox, Juan Martín «el Empecinado» o Espoz y Mina.

\section{Secundaria 2000. Historia. $2 .^{\circ}$ ciclo (1998)}

Un equipo de trabajo, dirigido por Rafael Valls, fue el autor de este manual editado por Santillana en 1998, ocho después de la promulgación de la LOGSE. El manual está dedicado enteramente a la Historia contemporánea, tanto universal como española, dedicando a esta última los seis últimos temas, de los 17 que lo conforman.

El momento que nos ocupa, la Guerra de la Independencia, aparece tratado en el tema 12: "Guerra y revolución». ${ }^{39}$ Llama la atención la notable ausencia de nombres propios, tan abundantes en épocas pretéritas. Por el contrario, se incide en el protagonismo de instituciones como las Juntas Provinciales y la Junta Central. Nada se lee ya acerca de aquellos héroes populares, tan elogiados en manuales de otras épocas, como Juan Martín, Andrés Torrejón, Espoz y Mina o los capitanes Daoíz y Velarde. Por el contrario, se dedica un espacio importante a la labor legislativa de las Cortes de Cádiz, especialmente a las medidas de carácter económico como la supresión de los mayorazgos o las desamortizaciones. Resulta evidente, a la vista del espacio dedicado a una y otra cuestión, que el manual incide mucho más en la revolución política y social que quisieron llevar a cabo las medidas novedosas promulgadas en Cádiz, que en el carácter heroico del pueblo y el ejército español en su resistencia a los invasores franceses. Aquel patriotismo que latía, como vimos, especialmente

${ }^{38}$ Castejón, Díez y Mascaró, Sociedad 80. 8. ${ }^{\circ}$ EGB, 42.

${ }^{39}$ Rafael Valls et al., Secundaria 2000. Historia. 2. ${ }^{\circ}$ ciclo (Madrid: Santillana, 1998), 208-233. 
en el manual de los 70 tras las prolíficas enumeraciones de nombres propios que resistieron hasta dejar la vida ante los franceses, torna ahora en un relato mucho más aséptico del desarrollo de la guerra, explicado con un detallado mapa que refleja las principales batallas y los movimientos más destacados de ambos bandos.

Resultan curiosas, no obstante, las numerosas ilustraciones de tipo caricaturesco y satírico dedicadas a los franceses, tanto a Napoleón y su familia, como a su ejército, que podrían hallar acomodo ideológico en manuales de dos décadas atrás, debido a su carácter patriótico. No encontramos, no obstante, ninguna fotografía proclive a los llamados afrancesados.

\section{Historia. 4. ${ }^{\circ}$ ESO (2008)}

Teresa Grence, junto a otros autores, elaboraron este novedoso manual que Santillana dedicó a la historia contemporánea universal y española. Novedoso, decíamos, tanto en su estructura formal, como en sus elementos didácticos: cuadros de ampliación, glosarios, cuadros de ideas claves, fuentes primarias para analizar, etc.

El manual consta de 16 temas, siendo el quinto el dedicado a la España del XIX y, por lo tanto, en el que vamos a centrar nuestra atención para repasar la cuestión que nos ocupa. La Guerra de la Independencia aparece aquí tratada en tres páginas ${ }^{40}$ que nos ofrecen novedades interesantes como el bando que el general Murat promulgó el 2 de mayo de 1808. La cartografía utilizada, un mapa que representa el desarrollo de la guerra, se acompaña con una breve explicación de las tres fases de la misma. Algo, sin duda, novedoso.

Respecto a los nombres propios, estos han desaparecido absolutamente. No se encuentra ni un solo personaje con nombre y apellidos. Tenemos aquí una prueba del amoldamiento de los manuales del siglo XXI a la preponderancia de nuevas corrientes historiográficas, más centradas en los procesos sociales y mentales, y alejadas de la concepción más factual, política, bélica y memorística. Todo ello a pesar de la renovación de la historiografía reciente en el campo de la biografía política o la his-

\footnotetext{
${ }^{40}$ Teresa Grence et al., Historia. $4 .^{\circ}$ ESO (Madrid: Santillana, 2008), 97-99.
} 
toria de las mujeres, por ejemplo. ${ }^{41}$ Así, el único personaje que aparece nombrado, y solo en una ocasión, es José Bonaparte. Si merece la pena destacar, como elemento novedoso, la introducción de un somero glosario que intenta explicar a los escolares el significado de los conceptos «afrancesados», «fernandinos»y «guerrillas».

\section{EDICIONES SM}

\section{Historia Universal y de España. 8. ${ }^{\circ}$ EGB (1979)}

Juan Rastrilla Pérez realizó para SM el siguiente manual, concebido para escolares de $8 .^{\circ}$ de EGB de finales de los setenta y principios de los ochenta. Treinta y cinco temas forman la totalidad del manual pero únicamente once se refieren a Historia de España. Una historia que abarca desde la llegada de los Borbones a España hasta la democracia que sucede a la muerte de Franco.

Nos interesa el tema 4: "Guerra, revolución y reacción en España» ${ }^{42}$ que recoge el desarrollo de la Guerra de la Independencia contra Francia, de las Cortes de Cádiz y, ya al final y de forma muy somera, del reinado de Fernando VII. Tras comentar la llegada de los franceses a España y la revuelta del Dos de mayo en Madrid, se dedica un epígrafe en exclusiva a hablar de los episodios más destacados de la Guerra de la Independencia. Entre ellos se destaca, muy especialmente, la batalla de Bailén, ganada por el general Castaños, la victoria de Los Arapiles y las victorias de Vitoria y San Marcial.

Una vez más, al tratar de estos asuntos, se destacan las formas tácticas de los españoles de afrontar la guerra, es decir, los asedios y las guerrillas. Como siempre, entre los asedios se destacan el de Gerona y el de Zaragoza, con un protagonismo indiscutible del general Palafox, al que incluso se le dedica una foto:

Zaragoza hubo de sufrir dos asedios y fue defendida por el general José Palafox. Agustina de Aragón tuvo un comportamiento

41 Elena Hernández Sandoica, Tendencias historiográficas actuales. Escribir historia hoy (Madrid: Akal, 2004). Entre otros autores que se han acercado al género biográfico podemos mencionar a Isabel Burdiel, Isabel II. Una biografía (1830-1904) (Madrid: Taurus, 2010).

42 Juan Rastrilla Pérez, Historia Universal y de España. 8. ${ }^{\circ}$ EGB (Madrid: Ediciones SM, 1979), 36-43. 
heroico en la defensa de la plaza. Destrozada la ciudad y sin recursos, los zaragozanos firmaron una honrosa capitulación. ${ }^{43}$

Un gran alegato patriótico, en el que se ensalzan las victorias españolas como fundamentales para que toda Europa tomara conciencia de que se podía derrotar a Napoleón, corona el espacio dedicado a la guerra:

Las victorias españolas, sobre todo las de Bailén y las heroicas defensas de Zaragoza y Gerona, tuvieron una gran influencia moral sobre los españoles, a los que dio una gran fe en la victoria, y sobre Europa entera, a la que lanzó a la lucha por su liberación al demostrarle que los ejércitos de Napoleón no eran invencibles y que sus famosos mariscales eran impotentes para vencer la resistencia heroica de un pueblo que defendía su independencia. ${ }^{44}$

A las Cortes de Cádiz y la Constitución de 1812 únicamente se les dedica un breve epígrafe en el que lo más destacado es la reflexión final acerca del porqué del fracaso de esta Constitución; reflexión en la que se «culpa» a un pueblo poco ilustrado que no buscaba la libertad:

Esta Constitución va a fracasar, ya que el pueblo carecía en 1808 de ilustración y de inquietud política, y era de sentimiento patriótico, monárquico, tradicional y católico. Era claro, pues, el desfase entre la revolución política de los dirigentes burgueses y la realidad social de una masa popular que había combatido por unos ideales concretos y primarios: por su casa, por su Dios y por su rey. ${ }^{45}$

El tema acaba con el reinado de Fernando VII, al que no se le dedica demasiado espacio. Se resume en sus problemas gravísimos con los liberales y la Constitución, sus contradicciones, la ayuda que recibió de la Santa Alianza para restaurar su autoridad tras el levantamiento de Riego que le obligó durante tres años (1820-1823) a aceptar la Constitución y, especialmente, el problema sucesorio que se desató entre su hija Isabel y su hermano Carlos María Isidro y que desembocó en las guerras carlistas.

\footnotetext{
${ }^{43}$ Rastrilla Pérez, Historia Universal y de España. 8. ${ }^{\circ}$ EGB, 39.

${ }^{44}$ Rastrilla Pérez, Historia Universal y de España. 8. ${ }^{\circ}$ EGB, 40.

45 Rastrilla Pérez, Historia Universal y de España. 8. ${ }^{\circ}$ EGB, 41.
} 
Entre las actividades planteadas, merece la pena destacar, por su originalidad, la siguiente:

Dibuja un mapa de España sobre la Guerra de la Independencia. Señala con círculos los focos de resistencia y con puntos las principales batallas ganadas por el ejército español.

El manual también suele adjuntar algún texto significativo en el capítulo de actividades. En este caso se nos insertan algunos artículos destacados de la Constitución de 1812 y un codicilo de Fernando VII en el que rectifica su anterior decisión de derogar la llamada Pragmática Sanción, que capacitaba a su hija Isabel para reinar en España.

\section{Milenio $4 .^{\circ}$ ESO (2003)}

Joan Santacana y Gonzalo Zaragoza son los autores que realizaron el proyecto Milenio de la Editorial SM destinado a los alumnos de $4 .^{\circ}$ de la ESO. Los diecinueve temas del libro intercalan epígrafes de historia europea y mundial con otros referidos a España. De hecho, se inserta el periodo bélico entre franceses y españoles dentro del ámbito internacional. Esta visión nos parece más acertada para entender el proceso revolucionario en su dimensión europea y cómo la guerra de Independencia contra las tropas napoleónicas fue un episodio más de respuesta del absolutismo frente a la Francia revolucionaria.

La Guerra de la Independencia disfruta de un reducido espacio en el tema 6 («De la sociedad tradicional a la revolución liberal (1776-1815)»). ${ }^{46}$ En él nos encontramos un Dos de mayo contando en cuatro párrafos de una manera nada pasional, «objetivista», despojada de aquellos nombres heroicos que los antiguos textos ensalzaban. El patriotismo, el orgullo nacional, el ensalzamiento de los nombres propios de la Historia de España, se van difuminando cada vez más en los nuevos manuales y este no es una excepción. Veamos, a modo de ejemplo, cómo el manual de 2003 relaciona la salida de los ejércitos de Napoleón de España con sus derrotas en Rusia y cómo, sin embargo, la misma SM en 1979 trataba estos asuntos desde un prisma mucho más «patriota»:

\footnotetext{
${ }^{46}$ Joan Santacana y Gonzalo Zaragoza, Milenio. Ciencias Sociales. Historia. $4 .^{\circ}$ ESO (Madrid: Ediciones SM, 2003), 92-109.
} 
Los ejércitos imperiales jamás pudieron ejercer un control sobre la totalidad del país, y cuando Napoleón empezó a cosechar derrotas en Rusia se vio obligado a retirar a su ejército de España.

Las victorias españolas, sobre todo las de Bailén y las heroicas defensas de Zaragoza y Gerona, tuvieron una gran influencia moral sobre los españoles, a los que dio una gran fe en la victoria, y sobre Europa entera, a la que lanzó a la lucha por su liberación al demostrarle que los ejércitos de Napoleón no eran invencibles y que sus famosos mariscales eran impotentes para vencer la resistencia heroica de un pueblo que defendía su independencia. ${ }^{47}$

Una vez más, el manual tiene el acierto de brindarnos dos textos de época para complementar el estudio de la Guerra de Independencia: el testimonio de un general francés (el Conde de Ségur) y el testimonio de un escritor español, José María Blanco White.

\section{Zenit $4 .^{\circ}$ ESO (2003)}

Algunas editoriales lanzaron al mercado de forma simultánea dos líneas comerciales, con la idea de plasmar contenidos más conceptuales que procedimentales y que podía tener una explicación económica, según su utilización fuera enfocada en un centro educativo público o privado. En el caso del proyecto Zenit, cuyos autores fueron M. ${ }^{\mathrm{a}}$ Antonia García Fuertes, Sara Navas San-Millán y Belén Pallol Trigueros, el tema de la Guerra de la Independencia queda diluido en el epígrafe «El fin del Antiguo Régimen», en la unidad 7 dedicada al estudio de España en el siglo XIX. ${ }^{48}$ El epígrafe se resuelve con tres subepígrafes que subdividen el periodo en el reinado de Carlos IV, la Guerra de Independencia y las Cortes de Cádiz. Se acompaña la doble página con un mapa de la Península que aúna los principales acontecimientos bélicos y las rutas seguidas por los ejércitos español, británico, portugués y francés, junto a algunos artículos de la Constitución de 1812.

\footnotetext{
${ }^{47}$ Santacana y Zaragoza, Milenio. Ciencias Sociales. Historia. $4 .^{\circ}$ ESO, 102 y Rastrilla Pérez, Historia Universal y de España. 8. ${ }^{\circ}$ EGB, 40.

${ }^{48}$ María Antonia García Fuertes, Sara Navas San-Millán y Belén Pallol Trigueros, Zenit. Historia. $4 .^{\circ}$ ESO (Madrid: Ediciones SM, 2003).
} 


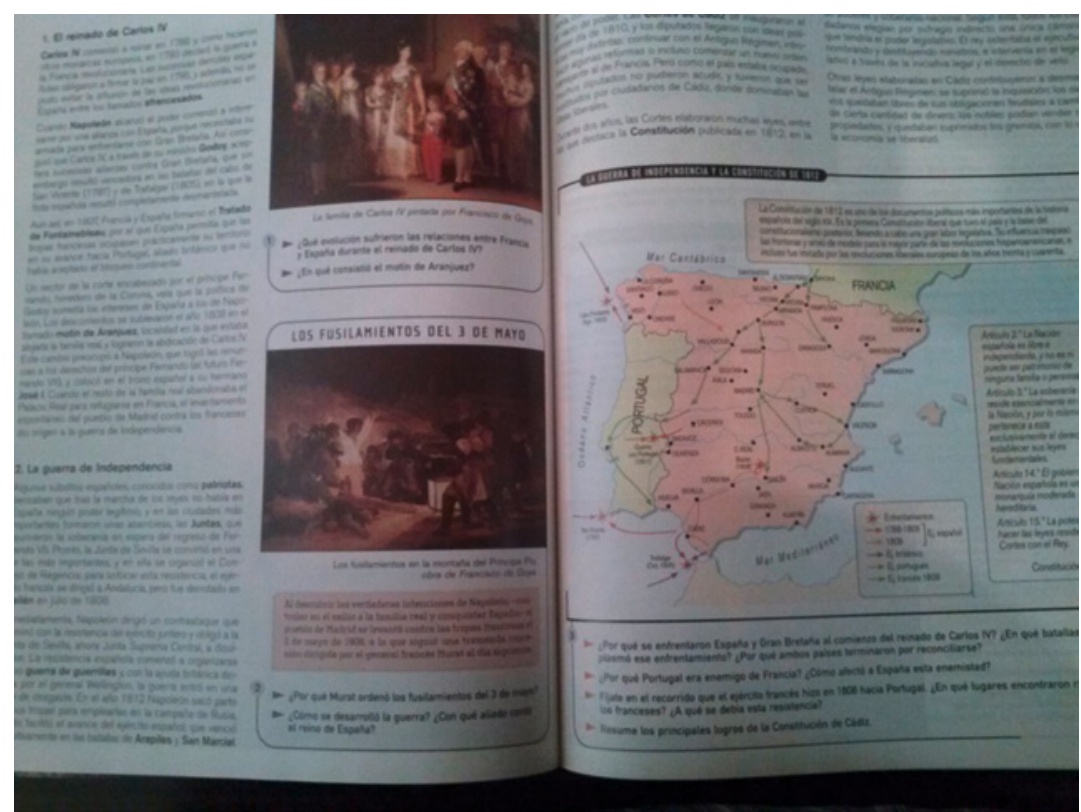

Figura 4. Ciencias Sociales, Zenit, Ediciones SM, 4. ${ }^{\circ}$ ESO (2003)

Entre los conceptos clave destacan algunas como «patriotas», Juntas, guerra de guerrillas y se menciona los enfrentamientos emblemáticos de Bailén, Arapiles y San Marcial. Entre los protagonistas, apenas una mención al general Wellington para apoyar la resistencia española.

En las actividades se introduce el llamado «catecismo» español de 1808 que pone de relieve con una estructura de preguntas y respuestas con duros calificativos para el emperador francés y odio a los franceses, más propio de contenidos de décadas pretéritas que del marco curricular en el que se contextualiza como eje transversal la educación para la paz:

- ¿Es pecado asesinar a un francés?

- No, padre, se hace una obra meritoria librando a la patria de esos violentos opresores. 


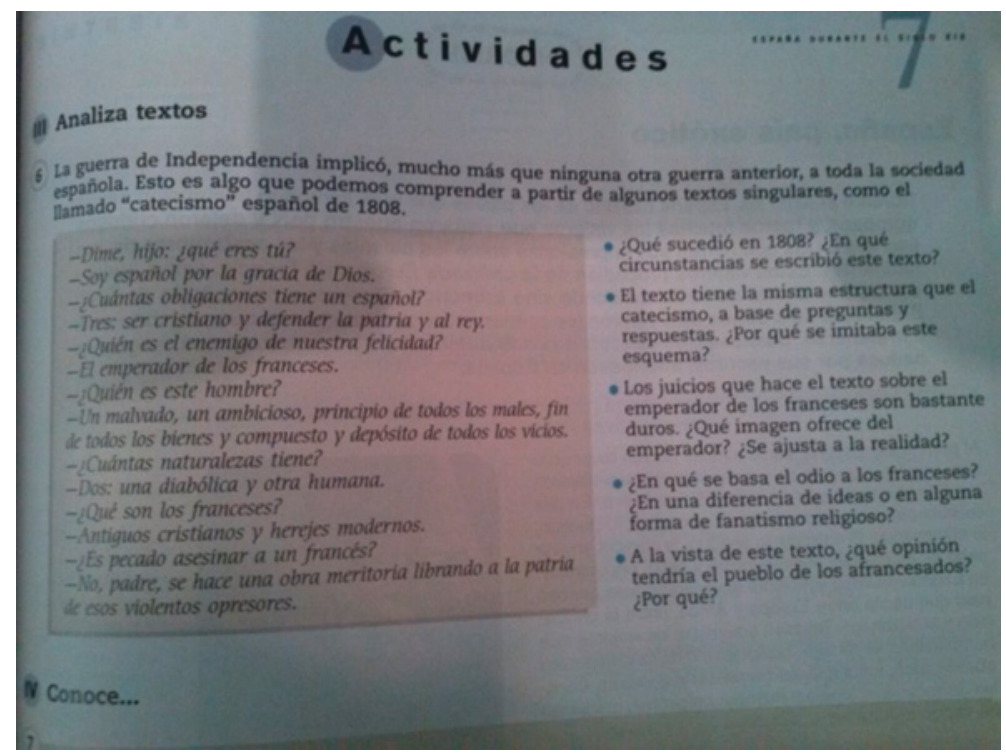

Figura 5. Ciencias Sociales, Zenit, Ediciones SM, 4. ${ }^{\circ}$ ESO (2003)

Es destacable reseñar cómo en las distintas ediciones autonómicas del sello se explayan acontecimientos propios de las Comunidades Autónomas. En el caso analizado, la Comunidad de Madrid, dedica un cuadro de contenido detallado al levantamiento popular del Dos de mayo, contenido perfectamente universalizable dentro de los currículos de legislaciones precedentes.

\section{OTRAS EDITORIALES}

\section{Ciencias Sociales. 8. ${ }^{\circ}$ EGB. Vicens Vives (1988-1991)}

Antonio Fernández, Montserrat Llorens, Rosa Ortega, José Pons, Joan Roig y Juan Carlos García Borrón son los autores de este manual de Vicens Vives para 8. ${ }^{\circ}$ de EGB. El libro está formado por 38 temas, 31 de los cuales están dedicados enteramente a Historia, quedando los 7 últimos para la ya habitual «Educación ética y vial». Los temas de Historia abarcan desde finales del siglo XVIII hasta fines del XX.

Es un libro que hace un abundante uso de fotografías y gráficos para completar las explicaciones que se van dando. En torno al $50 \%$ de su 
espacio está dedicado a tal fin. El primero de los temas que abordan la historia la historia propiamente española es el tema 4: «El reinado de Fernando VII, independencia de la América española». ${ }^{49}$ Se abre esta unidad con el epígrafe "Las Cortes de Cádiz», en el que se trata la cuestión de las Juntas Revolucionarias con un tono claramente patriótico, tal y como podemos ver nada más iniciar la cuestión:

En 1808 España estaba invadida por el ejército francés. El alzamiento de los españoles contra los invasores fue espontáneo en los primeros días, como el 2 de mayo en Madrid. ${ }^{50}$

Enseguida se hace notar la división interna de las Cortes de Cádiz en dos grupos: los absolutistas y los liberales, siendo éstos últimos mayoría por lo que la Constitución que emanó de esas Cortes tuvo un carácter liberal al introducir las ideas de «soberanía nacional» y «división de poderes». Unas ideas que los autores definen así:

Soberanía nacional: La Constitución sostiene que el verdadero soberano es la nación, y el rey solamente una institución que debe gobernar en beneficio del pueblo. Supone el rechazo del absolutismo.

División de poderes: Para evitar cualquier tentación de tiranía, el poder ha de estar repartido. Al rey y al gobierno les correspondería el poder ejecutivo, pero el poder legislativo (aprobación de las leyes) radicaba en las Cortes, y el poder judicial en los tribunales. ${ }^{51}$

Pero la vuelta de Fernando VII «frustró pronto las esperanzas de los españoles» y provocó, en palabras de los autores del manual, «un reinado de tensión constante entre partidarios y enemigos de la Constitución». Se acusa a Fernando VII de la persecución sistemática a los liberales y

\footnotetext{
${ }^{49}$ Antonio Fernández, Montserrat Llorens, Rosa Ortega, José Pons, Joan Roig y Juan Carlos García Borrón, Ciencias Sociales. 8. ${ }^{\circ}$ EGB (Barcelona: Vicens Vives, 1988), 36-45.

${ }^{50}$ Fernández et al., Ciencias Sociales. $8 .^{\circ} \mathrm{EGB}, 37$.

${ }^{51}$ Fernández et al., Ciencias Sociales. $8 .^{\circ} \mathrm{EGB}, 38$.
} 
de la restauración del tribunal de la Inquisición y se le tacha de tener un carácter «abotargado y engolado». 52

Tras los seis primeros años de reinado absolutista (1814-1820), llega el pronunciamiento del coronel Riego (1 de enero de 1820) mediante el cual se proclamó la vigencia de la Constitución de Cádiz de 1812, que Fernando VII había derogado mediante un decreto a su llegada a España. Se da comienzo así al llamado «trienio liberal», una etapa que es juzgada con evidente amabilidad por los autores. Así se comprueba en las siguientes líneas:

Los liberales iniciaron una etapa de reformas rápidas: supresión de la Inquisición, reducción del diezmo a la mitad (para abaratar los artículos de consumo), libertad de imprenta [...].

El ambiente revolucionario se vivió con fervor de exaltación. En los clubes denominados Sociedades patrióticas se leía la Constitución y la prensa, se discutía de política y se repartían sopas a los pobres. Entretanto los partidarios del rey conspiraban. ${ }^{53}$

En contraposición, esta es la visión que se da de los partidarios absolutistas:

La contrarrevolución fue apoyada por la mayoría de los obispos y clero, exasperados por las medidas anticlericales de los liberales, por un grupo de diputados absolutistas y por bandas de campesinos armados, mezcla de guerrilleros y bandoleros.

Finalmente se restaura el absolutismo gracias a la intervención de un ejército francés, los llamados Cien mil hijos de San Luis, al mando del duque de Angulema. Empieza así un decenio llamado ominosa década y definido así por los autores: «decenio abominable, caracterizado por la intensificación del despotismo».

52 Fernández et al., Ciencias Sociales. 8. ${ }^{\circ}$ EGB, 38.

${ }^{53}$ Fernández et al., Ciencias Sociales. 8. ${ }^{\circ}$ EGB, 40. 


\section{Ciencias Sociales. $4 .^{\circ}$ ESO. Teide (1995)}

Elaborado por Francisco Xavier Hernández, este manual está escrito enteramente en catalán y se enmarca dentro de un plan educativo distinto, la LOGSE, que vino a sustituir a la Ley General de Educación de 1970 veinte años después. Es llamativo cómo presenta el autor a los alumnos la Guerra de la Independencia entre España y Francia. El epígrafe que se ocupa de la misma es denominado «La guerra peninsular», una forma como cualquier otra de desmarcar a los catalanes del resto de españoles y sus aconteceres bélicos. Abundando en esta idea, y ya metidos en la explicación, encontramos la siguiente justificación de semejante título, una justificación que lleva aparejada una vez más la idea de que los españoles son una cosa y los catalanes otra:

La guerra va a ser objeto de numerosas denominaciones; los catalanes la van a denominar guerra del francés; los españoles, guerra de la Independencia, los franceses, guerra de España, y los ingleses, guerra peninsular. ${ }^{54}$

Más allá de las denominaciones, parece de suma importancia remarcar la ridícula dualidad que, una vez más, encontramos; pues, si bien apenas nada se dice de los hechos heroicos que los españoles llevaron a cabo contra los franceses, ni se destaca a ningún nombre particular y legendario como pudieran ser los de Juan Martín «el Empecinado», Manolita Malasaña o los capitanes Luis Daoíz y Pedro Velarde, sí se dedican dos páginas enteras y cuatro fotos a hablar de la relación entre Napoleón y Cataluña, así como de la idea de éste de Cataluña como algo separado, ajeno e independiente de España:

Siguiendo instrucciones de Napoleón, Cataluña se separaría de los dominios del rey de España José I, y se constituía un Gobierno de Cataluña. ${ }^{55}$

En este mismo tema, ya en la parte de las actividades, nos encontramos con un mapa de la Europa del momento en el que se diferencia, con distintos colores a España, Francia, Portugal, Italia, Reino Unido, etc. y... ¡iCataluña!!, a la que, de esta manera, se da rango de nación independiente.

${ }^{54}$ Francisco Xavier Hernández, Ciencias Sociales. 4. ${ }^{\circ}$ ESO (Barcelona: Teide, 1995), 164.

${ }^{55}$ Hernández, Ciencias Sociales. $4{ }^{\circ}$ ESO, 166. 

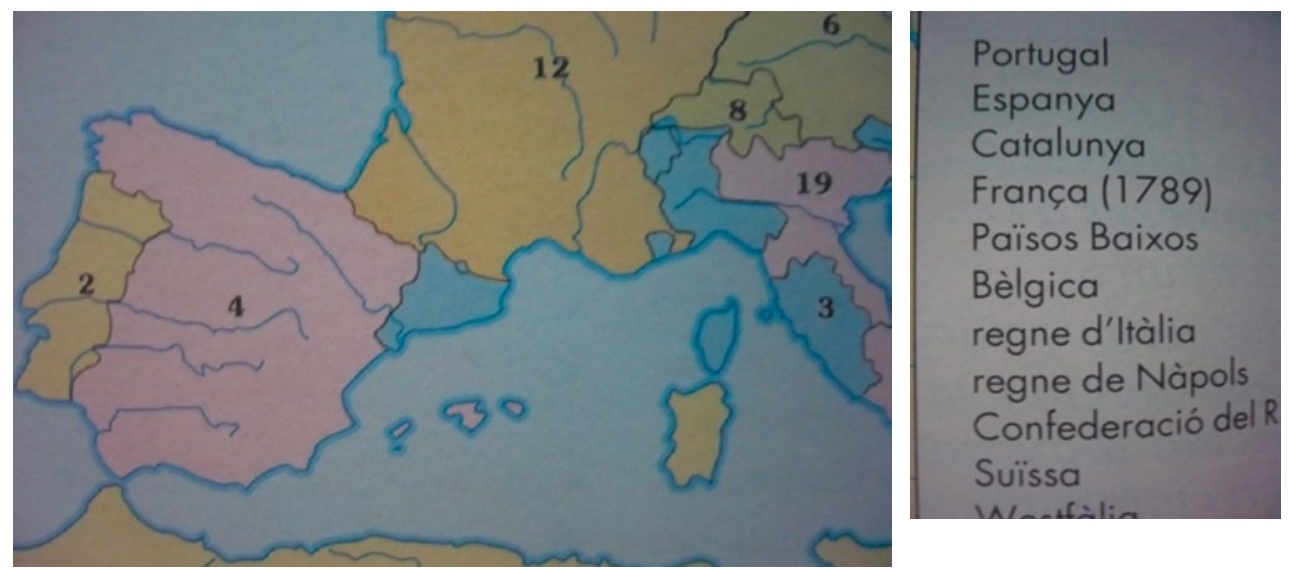

Figuras 6 y 7. Ciencias Sociales. $4 .^{\circ}$ ESO. Teide (1995)

\section{Geografía e Historia. $4 .^{\circ}$ ESO. Editorial Erein (1999)}

Vamos también a centrar nuestra atención en una editorial exclusivamente vasca: Erein. Una editorial con sede en San Sebastián, ciudad desde donde distribuye sus manuales por todo el País Vasco. Manuales que han sido frecuentes objetos de polémica por sus contenidos, fundamentalmente en el área de Ciencias Sociales, Geografía e Historia, por sus posiciones habitualmente cercanas al nacionalismo vasco más adoctrinador. Posiblemente, estamos aquí ante uno de los más claros ejemplos de editoriales de ámbito autonómico puestas al servicio de un «currículum oculto».

Explicado esto, vamos a repasar uno de los manuales de Geografía e Historia que esta editorial ofrecía a los alumnos de $4 .^{\circ}$ de la ESO a finales de los noventa. El manual está, eso sí, editado en castellano, suponemos que por motivos comerciales.

Sus autores son Ramón Leturiondo, Eduardo Pérez, Alberto Prego, Claudio Rodríguez y Juan Manuel Rodríguez y consta de cuatro bloques temáticos, siendo el segundo de ellos el único dedicado a Historia. Una Historia que nos habla de los siglos XIX y xx tanto en Europa, como en España y en... Euskal Herria, tratada aquí de forma completamente independiente a España, palabra ésta que, por cierto, aparece bastante poco. Se transmite desde el sumario la idea de naciones independientes. 
Veamos, qué explicaciones se dan acerca del siglo XIX en España. Éstas aparecen en el tema 2 del bloque 2: «El siglo XIX en España». ${ }^{56}$ Como sabemos, el siglo XIX en España se inició bajo el reinado de Carlos IV (1789-1808) pero nada se explica de sus casi veinte años de reinado. La invasión francesa de España y la posterior Guerra de la Independencia son tratados muy someramente y, por supuesto, no se da pie a ningún tipo de ardor patriótico ni elogio de la combatividad de los españoles contra los franceses. Aquellos héroes que nos mostraban los antiguos manuales están absolutamente desaparecidos. No solo eso, sino que se procura restar méritos a las armas españolas, incidiendo en la importancia de la ayuda inglesa:

tras cinco años de incesante lucha, y gracias a la colaboración del ejército inglés, los franceses tuvieron que retirarse del suelo peninsular. ${ }^{57}$

Por último, el reinado de Fernando VII es explicado muy someramente en pocos párrafos y de manera negativa.

\section{CONCLUSIONES}

Los libros de textos deben facilitar la comprensión del presente, contribuir al desarrollo de las facultades intelectuales, enriquecer otros temas del currículo y ayudar a adquirir sensibilidad social. En aras de un proceso de enseñanza-aprendizaje que incluya el desarrollo del espíritu crítico en los alumnos, algunos libros de textos muestran héroes de todos los personajes históricos y posibilitan la construcción de una memoria colectiva desde el ámbito escolar y han arrinconado - $\mathrm{O}$ al menos han equiparado el espacio dedicado a su exposición- los acontecimientos y procesos políticos al análisis de los mismos bajo el prisma de la causalidad histórica.

A través de los contenidos sobre la Guerra de la Independencia, estos cambios se perciben con claridad en las editoriales consultadas y podemos resumirlos, fundamentalmente, en dos puntos: una disminución

${ }^{56}$ Ramón Leturiondo, Eduardo Pérez, Alberto Prego, Claudio Rodríguez y Juan Manuel Rodríguez, Geografía e Historia. $4 .{ }^{\circ}$ ESO (Donostia: Editorial Erein, 1999), 72-78.

${ }^{57}$ Leturiondo et al., Geografía e Historia. $4 .^{\circ}$ ESO, 72. 
progresiva de las páginas dedicadas a la historia política y, sobre todo, un cambio muy claro en la manera de explicar estos asuntos. Cuestiones a las que antes se dedicaban varios temas, fotografías y actividades han ido, poco a poco, viendo reducido su protagonismo a unos pocos párrafos insertados en temas de carácter más general. Podemos buscar la explicación a esta realidad en los cambios historiográficos que ha ido experimentando la disciplina. Aquella historia narrativa ha ido siendo sustituida por otra de carácter más social o económico. Un cambio de óptica en el que no encuentran fácil acomodo la profusión de nombres propios, de héroes y batallas, que aparecían en los textos de hace décadas.

Pero hay que buscar también una explicación política. En los años setenta estos asuntos se usaban como blasón de la España orgullosa, de la España independiente. Los textos transmitían el orgullo por Palafox, Daoíz y Velarde, Manuela Malasaña y tantos otros. La reacción de los españoles contra los franceses era motivo de orgullo y prestigio y en ningún caso se aludía a estos temas desde una visión fría y objetivista. Todo esto fue primero matizándose y, más adelante, girando. Hemos observado cómo, desde la segunda mitad de los ochenta, y muy especialmente a partir de los noventa, va a ir despareciendo de los textos la anterior profusión de nombres propios y momentos históricos (Dos de mayo, los sitios de Gerona o Zaragoza, el asedio a Cádiz...), sustituida ahora por visiones más regionales de estos asuntos. Es decir, serán tratados en mayor o menor medida, dependiendo de la autonomía para la que haya sido elaborado el libro de texto. Por ejemplo, en ediciones del País Vasco, apenas encontramos nada del Dos de mayo madrileño.

Igual de significativa es la evolución más equilibrada de los contenidos de los manuales que se dividen en cuestiones políticas, institucionales y bélicas, económicas, sociales, artísticas y culturales. Como consecuencia de esto, la historia de nombres propios (reyes, batallas, tratados, etc.) propia de una historiografía nacionalista ha ido cediendo terreno, sobre todo, a la explicación de unos procesos políticos, económicos, sociales y culturales concatenados por la multicausalidad histórica. 


\section{Nota sobre los autores:}

José Ignacio Ortega Cervigón es docente e investigador en el Departamento de Didáctica de la Ciencias Sociales de la Universidad Complutense de Madrid. Doctor en Historia Medieval por la Universidad Complutense de Madrid, ha publicado una treintena de trabajos de investigación (capítulos de libros, artículos científicos y comunicaciones) relacionados con la nobleza castellana medieval y la didáctica de la historia. En este ámbito sus principales líneas versan sobre las fuentes documentales en la enseñanza de la Historia y el análisis de libros de texto de Ciencias Sociales.

JuAn Esteban Rodríguez GaRrido es Doctor en Educación por la Universidad Complutense y Licenciado en Historia por esta misma Universidad. Actualmente es profesor asociado del Máster para la Formación del Profesorado en la Universidad Nebrija. Ha sido profesor entre 2008 y 2016 en la Facultad de Educación de la UCM. Asimismo ha sido profesor invitado en las Universidades de Oporto, Granada y Murcia. Miembro del CITCEM-Centro de Investigaçao Transdisciplinar «Cultura, Espaço e Memoria», vinculado a la Universidad de Oporto y del grupo Cine y Letras, vinculado a la Universidad de Granada. Autor del libro Trato y maltrato de la Historia de España en los libros de texto de la EGB y la ESO (Editorial Académica Española, 2012) y de diferentes artículos relacionados con el tratamiento de la Historia en los libros de texto y acerca de la relación entre Historia y Literatura.

\section{Referencias}

ARranz Márouez, Luis, coord. Actas del 5. ${ }^{\circ}$ Congreso sobre el libro de texto y materiales didácticos. Madrid: Universidad Complutense, 1997.

- Monográfico. Ensayos. Revista de la Facultad de Educación de Albacete 29 (1) (2014).

- Monográfico. Los libros de texto. Revista Iber. Didáctica de las ciencias sociales, geografía e historia 70 (2011).

BuRDIEL, Isabel. Isabel II. Una biografía (1830-1904). Madrid: Taurus, 2010.

HERnÁNDEZ SANDOICA, Elena. Tendencias historiográficas actuales. Escribir historia hoy. Madrid: Akal, 2004.

LEÓn Guerrero, María Montserrat. «Evolución de la Geografía y la Historia en los libros escolares». In Una mirada al pasado y un proyecto de futuro. Investigación e innovación en didáctica de las ciencias sociales, edited by Joan 
Pagès i Blanch and Antoni Santisteban Fernández. Barcelona: Universitat Autónoma de Barcelona, 2013.

MAnZANo MoReno, Eduardo. «La construcción del pasado nacional». In La gestión de la memoria. La Historia de España al servicio del poder, edited by Juan Sisinio Pérez Garzón, 48-61. Barcelona: Crítica, 2000. Miralles, Pedro, Sebastián Molina and Jorge OrTuño. La importancia de la historiografía en la enseñanza de la historia. Granada: Grupo Editorial Universitario, 2011.

PAGÈs, Joan. «Enseñar a enseñar Historia: la formación didáctica de los futuros profesores de Historia». In Miradas a la Historia. Reflexiones historiográficas en recuerdo de Miguel Rodríguez Llopis, edited by María Encarna Nicolás Marín and José Antonio Gómez Hernández, 155-178. Murcia: Universidad de Muria, 2004.

- «Líneas de investigación en didáctica de las ciencias sociales». In Enseñary aprender Ciencias Sociales, Geografía e Historia en la educación secundaria, edited by Pilar Benejam and Joan Pagès, 209-226. Barcelona: ICE de la Universidad de Barcelona, Horsori, 1997.

PÉrez Garzón, Juan Sisinio, coord. La gestión de la memoria. La Historia de España al servicio del poder. Barcelona: Crítica, 2000.

- «La creación de la Historia de España». In La gestión de la memoria. La Historia de España al servicio del poder, edited by Juan Sisinio Pérez Garzón, 96-108. Barcelona: Crítica, 2000.

Prats Cuevas, Joaquín. «Dificultades para la enseñanza de la Historia en la Educación Secundaria: reflexiones ante la situación española». Revista de Teoría y Didáctica de las Ciencias Sociales 5 (2001): 71-98.

Prats, Joaquín, y Joan SANTACANA. "Trabajar con fuentes materiales en la enseñanza de la historia». In Geografía e Historia: investigación, innovación y buenas prácticas, edited by Joaquín Prats, 11-37. Barcelona: Graó, 2011.

Prats, Joaquín, y Rafael VALLS. «La Didáctica de la Historia en España: estado reciente de la cuestión». Didáctica de las Ciencias Experimentales y Sociales 25 (2011): 17-35.

Prats, Joaquín, José Emilio Castelló, María Camino García, Ignacio Izuzquiza, María Antonia Loste and Montserrat Pongiluppi. Historia. 2. $^{\circ}$ ciclo ESO. Madrid: Anaya, 1998.

Rastrilla PÉrez, Juan. Historia Universal y de España. 8. ${ }^{\circ}$ EGB. Madrid: Ediciones SM, 1979.

RIVIÈRE Gómez, Aurora. «Envejecimiento del presente y dramatización del pasado. Una aproximación a las síntesis históricas de las Comunidades Autónomas españolas (1975-1995)». In La gestión de la memoria. La Historia de 
España al servicio del poder, edited by Juan Sisinio Pérez Garzón, 161-219. Barcelona: Crítica, 2000.

Rodríguez GaRrido, Juan Esteban. Trato y maltrato de la Historia de España en los libros de texto. Desde 1970 hasta nuestros días. Madrid: Editorial Académica Española, 2012.

SÁIz SERRANO, Jorge. «Fuentes históricas y libros de texto en secundaria: una oportunidad perdida para enseñar competencias de pensamiento histórico». Ensayos. Revista de Educación de la Facultad de Albacete 29-1 (2014): 83-99.

- «Alfabetización histórica y competencias básicas en libros de texto de Historia y en aprendizajes de estudiantes». Didáctica de las Ciencias Experimentales y Sociales 27 (2013): 43-66.

Salazar Jiménez, Rodrigo, María Carmen Rojo Ariza and Virginia Gámez Ceruelo. «La Segunda República y la Guerra Civil española según los libros de texto de Cataluña a inicios del siglo XXI». In Una mirada al pasado y un proyecto de futuro. Investigación e innovación en didáctica de las ciencias sociales, edited by Joan Pagès i Blanch and Antoni Santisteban Fernández, vol. 2. Barcelona: Universitat Autònoma de Barcelona, 2014.

SoBRINo, Diego. «La enseñanza de la Constitución de Cádiz. Una experiencia en bachillerato desde la historia local». Iber. Didáctica de las Ciencias Sociales, Geografía e Historia 72 (2012): 47-56.

VALls, Rafael, Nicolás MarTínez y Francisco PinedA. «El uso del libro de texto en Historia de España en Bachillerato: diez años de estudio (1993-2003) y dos reformas (LGE-LOGSE)». Didáctica de las Ciencias Experimentales y Sociales 23 (2009): 3-35.

VALLS, Rafael. «La enseñanza de la Historia: entre polémicas interesadas y problemas reales Didáctica de la Historia en España: estado reciente de la cuestión». In Miradas a la Historia. Reflexiones historiográficas en recuerdo de Miguel Rodríguez Llopis, edited by María Encarna Nicolás Marín and José Antonio Gómez Hernández, 141-154. Murcia: Univesidad de Murcia, 2004.

- Enseñanza de la Historia y textos escolares. Buenos Aires: Libros del Zorzal, 2008. 